Revista de la red interuniversitaria de estudios sobre las literaturas rioplatenses contemporáneas en Francia

$9 \mid 2013$

Homenaje a Ana María Barrenechea

\title{
El exilio del monstruo
}

\section{Tomás Fernández}

\section{OpenEdition}

\section{Journals}

\section{Edición electrónica}

URL: http://journals.openedition.org/lirico/1208

DOI: 10.4000/lirico.1208

ISSN: 2262-8339

Editor

Réseau interuniversitaire d'étude des littératures contemporaines du Río de la Plata

\section{Referencia electrónica}

Tomás Fernández, «El exilio del monstruo », Cuadernos LIRICO [En línea], 9 | 2013, Publicado el 01

septiembre 2013, consultado el 22 septiembre 2020. URL : http://journals.openedition.org/lirico/1208 ; DOI : https://doi.org/10.4000/lirico.1208

Este documento fue generado automáticamente el 22 septiembre 2020

\section{c.) (i) (9)}

Cuadernos LIRICO está distribuido bajo una Licencia Creative Commons Atribución-NoComercialSinDerivar 4.0 Internacional. 


\section{El exilio del monstruo}

\section{Tomás Fernández}

\section{REFERENCIA}

Mandolessi, Silvana, Una literatura abyecta. Gombrowicz en la tradición argentina, Amsterdam - New York, Rodopi, 2012, 290 p. 
1 Conde clandestino y cultor de los malos modos, Witold Gombrowicz es peculiar desde sus inicios. Los críticos han subrayado, mayormente en tono de chiste, que ya su primer libro mencionaba proféticamente la lejana tierra de los gauchos: “¡Bajo el hermoso cielo de Argentina, los sentidos gozan gracias a una niña!" (66). ${ }^{1}$ Su difusión en dicho país - en el que permaneció entre 1939 y 1963 - le debe mucho a Ricardo Piglia, quien subraya su costado glorioso, heroico, estoico e irreverente. Sin embargo, Gombrowicz es mucho más que eso, y a la vez mucho menos. El autor polaco, como César Aira - el gran excluido en este libro que estudia la pervivencia de Gombrowicz en Argentina $-^{2}$, alterna fragmentos de obvia lucidez y sutileza incisiva con otros superficiales, como el siguiente: “Él

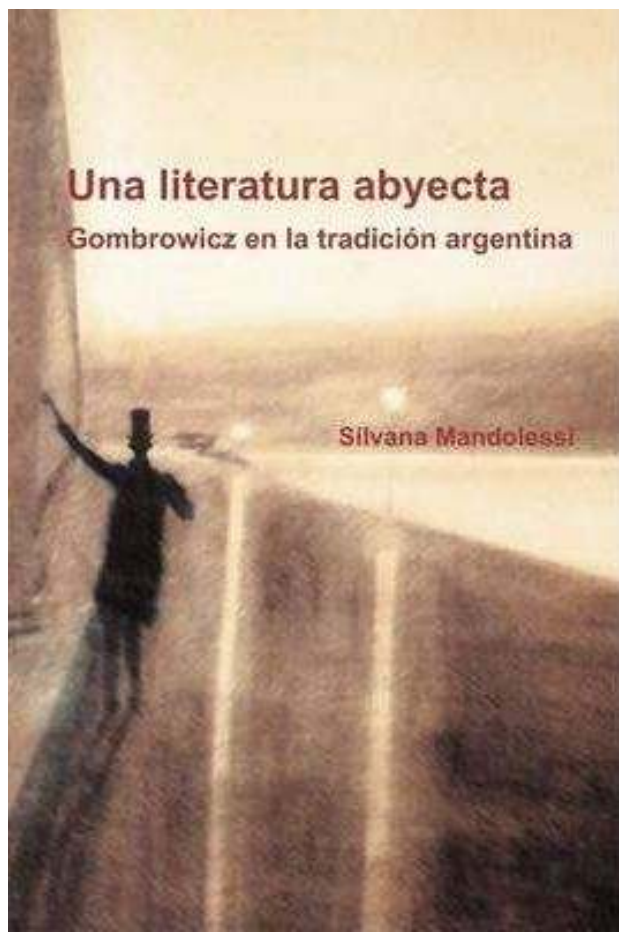
[Borges] se halla enraizado en la literatura, yo en la vida" (190; de Testamento). En otros escritores - a algunos de los cuales cita Alan Pauls en El factor Borges -, situar a Borges en el polo "literatura" de la remanida antítesis vida / literatura puede ser atribuido a simple facilismo, ingenuidad, distracción, ignorancia o ausencia de refinamiento conceptual. En Gombrowicz, cualquiera de estas opciones debe ser descartada. Tampoco sería acertado asignar sus "defectos" a un simple cálculo autoral, ya que en todo momento están signados, no por una supuesta autenticidad que este autor aborrece, sino por el exceso. Gombrowicz, en efecto, presenta a "Gombrowicz" como ridículo, caprichoso e idiota, y modela con toda paciencia un narrador desagradable, superando ampliamente las tentativas de alguien que propugnara el mal gusto meramente para sacudir las tradiciones establecidas. No es un simple amante del fracaso que ajusta medios a fines, como podría pensar un lector de Piglia. No es sólo alguien que recurre al asco para hacer temblar las convenciones, o a la inmadurez para poner en ridículo a la forma.

2 El libro de Mandolessi tiene la virtud de resaltar estas contradicciones fundantes ${ }^{3}$, que impiden asignar a Gombrowicz una figura única, reducirlo a eslóganes (eslóganes que, para colmo, pueden ser extremadamente ingeniosos, en un autor que jamás se rebajó a la inteligencia o la genialidad) o hacerlo objeto de un discurso unificado y coherente. En este sentido, un libro sobre Gombrowicz puede parecer una imposibilidad. Mandolessi, sin embargo, bordea con elegancia esta imposibilidad y ofrece un panorama sólido que se asienta sobre tres ejes claves: el concepto de abyección, la figura de Witold Gombrowicz y el constructo nacional que llamamos "Argentina”.

3 En el primer capítulo se discuten los alcances conceptuales del primero de estos términos. Una acepción apta es la provista por John Lechte (en su obra Julia Kristeva, de 1990): “[...] the abject is above all the ambiguous, the in-between, what defies boundaries, a composite resistant to unity" ; dicha definición reaparece a lo largo del libro (e.g., 203). El capítulo primero, sin embargo, profundiza en las diversas 
potencialidades del concepto, ocupándose en un primer término de la abyección como categoría psicoanalítica. Aquí, el centro es Julia Kristeva, en particular sus Pouvoirs de l'horreur (1980). Mandolessi subraya que "la expulsión de lo abyecto es una de las precondiciones de lo simbólico", pero también un "resto excesivo" que nunca se elimina (31) y que pertenece al reino de lo semiótico (34). Lo abyecto es lo indecidible, lo que desafía los límites, lo "otro". La abyección, por lo demás, "se identifica con una emoción visceral [...], el asco" (39), que ocupa un lugar importante en este capítulo, especialmente en su connotación política, la de apuntalar el buen gusto de los sectores dominantes : "[...] el asco es el mecanismo que sostiene la jerarquía" (43). Sigue un análisis del potencial político de la abyección, donde la figura prominente es Judith Butler. "La divergencia entre Kristeva y Butler en su concepción de la abyección explica Mandolessi- se sustenta en una divergencia entre sus respectivas concepciones de la subjetividad o, más específicamente, en la relación entre subjetividad y sociedad" (49). Los dos últimos apartados abordan la abyección como categoría estética, y en particular el fenómeno de lo feo. Aquí resurge con particular claridad la importancia del cuerpo y del detalle material en una estética de la abyección como la de Gombrowicz.

El segundo capítulo, "Abyección y asco : Bakakai", se centra en una obra donde aparecen in nuce temas centrales en Gombrowicz, como la sexualidad, la estética y el nacionalismo (67). Mientras en este libro se fustiga el "buen gusto" de las clases altas actitud que el Diario argentino famosamente replica -, se resalta el atractivo de lo feo, lo bajo y lo inmundo : ¿Era posible que sólo el pecado y la suciedad fueran profundos ?", se pregunta el protagonista del extraordinario cuento "En la escalera de servicio" (89). Conviene subrayar la discutible pertinencia de este capítulo para la discusión de la obra "argentina" de Gombrowicz. Simultáneamente, resulta extraño que el corpus incluya a Bakakaï pero no a Ferdydurke, cuya traducción argentina es de sobra conocida.

El tercer capítulo, "Abyección y subjetividad: Diario, Testamento y Peregrinaciones argentinas", es la clave de bóveda del ensayo de Mandolessi. Aquí aparece una de las grandes secciones de este libro : la consagrada a la comparación entre Gombrowicz y otros extranjeros ilustres en Argentina, especialmente Ortega y Gasset. El español señala que "acaso lo esencial de la vida [del argentino] es eso -ser promesa (146)." No conforme con esta afirmación, y ante el temor de ser acusado de vaguedad, abunda : "La forma de existencia del argentino es lo que llamaría el futurismo concreto de cada cual (146)." Obnubilado frente a las esquirlas de inteligencia civilizada que el celebrado Ortega y otros intelectuales de alto vuelo impartían sobre Argentina, Gombrowicz declara : "[...] se dice que Argentina no existe [...] o que existe como algo embrionario, doloroso [...], etcétera. Tales cosas, repetidas con demasiada frecuencia, me parecen poco veraces y harto exageradas" (144); o : "Se han escrito volúmenes enteros sobre la psicología del sudamericano, a veces metafísicos, casi siempre demasiado 'profundos' el conocimiento del hombre o de la nación no siempre es un pez de aguas profundas-" (154; ambos del Diario argentino). Estos juicios son inatacables. Si Gombrowicz acepta la juventud y la inmadurez de los argentinos es, por supuesto, para exaltarlas. No queda otra opción en un país donde el canillita que vocea una revista literaria tiene más estilo que todos los colaboradores de esa misma revista (165), y donde "únicamente el vulgo es distinguido" (165). El hombre americano, por lo demás, es "incapaz de asimilar teoría alguna" pero esto, lejos de ser un defecto, lo convierte "precisamente en el hombre del futuro" (163). También Gombrowicz se resiste a la teoría. Al mismo tiempo, rechaza toda tentación naturalista, y suele describir las ciudades como si fueran indiferenciables unas de otras. Tiene, en términos de Mandolessi -que en esto sigue a 
Piglia-, la mirada de un turista, opuesta a la mirada "profunda" de un verdadero viajero como Ortega y Gasset. No hay que engañarse: "Esta mirada 'superficial' del turista es una mirada estratégica" (157). No sólo eso : cuando Gombrowicz emite detalles concretos, revela una atención aguda a su entorno. La comida es espantosa, sin duda, pero en Argentina existe la ventaja de que "el obrero come más o menos lo mismo que el dueño de la fábrica" (160); al mismo tiempo, Argentina, "tan poco humanizada y tan salvaje [...] es, sin embargo, urbana hasta la médula" (160; ambas citas son de Perergrinaciones argentinas). No podría exagerarse el acierto de esas frases breves y contundentes, especialmente si se las contrasta con las afirmaciones de los borrosos extranjeros que encuentran en la pampa sin arar un símbolo de la potencialidad pura, jamás concretada, que caracterizaría a los argentinos. A nadie sorprenderá que, también en lo que concierne a un país, Gombrowicz se fije antes en el cuerpo que en el espíritu y evite, por consiguiente, extravíos sobre el misterioso "ser nacional" de los argentinos.

El cuarto capítulo, "Abyección y nación : Trans-Atlántico", forma una suerte de unidad con el anterior. Es conocida la obsesión de Gombrowicz por la forma y la inmadurez (o la antiforma). Esta última aparecía en el capítulo anterior en su relación con los escritos "autobiográficos", con todas las reservas que el concepto de "autobiografía" suscita en relación con yoes manifiestamente fraudulentos como los de Gombrowicz. En este capítulo, en cambio, la inmadurez es analizada desde la perspectiva de la más argentina de las novelas de Gombrowicz. Aquí aparece el notable contraste entre Borges y Gombrowicz, especialmente en su relación con el dilema entre la "civilización" y la "barbarie". Tanto en el excesivamente célebre "El escritor argentino y la tradición" (1955) como en su práctica narrativa, Borges superaría la oposición convirtiendo lo bárbaro en literatura y, por ende, en civilización. Según Graciela Montaldo, "[e]l campo y el gaucho borgianos son citas" ( 209 ; citado por Mandolessi) ; "bárbara puede ser - si lo es - la realidad, pero nunca lo serán las formas literarias" ( 210 ; citado por Mandolessi). El procedimiento de Gombrowicz para desactivar esta antítesis es más sutil. En un primer término, Gombrowicz apuesta "a la devaluación de la civilización, a una crítica de la alta cultura" (213). Esto no es más que tomar posición en el debate en beneficio de la barbarie, no desarticular la estéril oposición que mencionamos. La inmadurez, sin embargo, y por su propia dinámica, no puede tolerar oposiciones netas, que requieren de categorías fijas. Civilización y barbarie, extranjero y nacional, alto y bajo, terminan por ende disolviéndose en el barro de la indiferenciación : en lo abyecto. Este arco simbólico se aprecia en la trama de Trans-Atlántico, donde lo que parece un duelo a muerte entre los representantes de la "civilización" y los de la "barbarie" se resuelve en una explosión de risa subversiva. Nada más adecuado : lo bárbaro, como lo inmaduro, no tolera oposiciones netas, ni siquiera si éstas conducen a su propio triunfo.

7 El quinto capítulo, “Abyección y canon: Piglia lector de Gombrowicz", es el más problemático del volumen. Para empezar, la relación entre "abyección y canon" nunca es abordada de modo explícito, circunstanciado y sostenido. También es conflictivo el lugar que debe ocupar Tardewski, el personaje de Respiración artificial inspirado en Gombrowicz. Mandolessi admite la ausencia de abyección en él : "Gombrowicz, en Respiración artificial, no aparece como una figura abyecta". Con todo, agrega: "sin embargo, los tópicos de la abyección y lo siniestro son constitutivos en la novela" (273). Sin duda, pero no de un modo que presente semejanzas estructurales con el valor de estas categorías en Gombrowicz. Por lo demás, no se argumenta en qué medida, y por qué medios específicos, la abyección es "constitutiva en la novela". Queda sin explorar, 
al mismo tiempo, la muy marcada ausencia de abyección en la figuración de Tardewski, quizá más significativa que la (dudosa) abyección presente en la novela en su conjunto.

8 La tipología del exiliado en la novela de Piglia (257-274), en cambio, es de una pertinencia y originalidad muy claras. En Respiración artificial, escribe Mandolessi, hay al menos tres tipos de exiliados. Uno está figurado por el conde Tokray, que representa no tanto un país (la Rusia zarista) como un período histórico separado del presente por una infranqueable distancia ideológica. Tokray vive en un momento discontinuo, desgajado de toda sucesión ; encarna él mismo una suerte de imagen dialéctica al modo de Walter Benjamin, con la salvedad de que es algo nostálgico. El segundo tipo es el exiliado patriota y utopista: Enrique Ossorio, doble de Juan B. Alberdi. Si bien Mandolessi no lo señala explícitamente, puede agregarse el tipo del "exiliado interior", representado por alguien anclado en la historia, pero sin ningún lazo social fijo, evidentemente encarnado por Maggi, tío del protagonista. El tercer tipo, central para el análisis de Mandolessi, brilla con sus colores propios gracias al contraste con los anteriores. Se trata, obviamente, del exiliado que vive fuera de la historia : Tardewski/ Gombrowicz. (A éstos podrían sumarse los extranjeros no exiliados que pontifican sobre los países que visitan : Ortega y Gasset, Waldo Frank, el Conde de Keyserling.)

La "Conclusión", que en rigor constituye un laxo resumen, es excesivamente breve (279-282). Allí Mandolessi vuelve a explicar algunos de los conceptos clave de su libro. Agrega, sin embargo, un punto esencial: "En el quinto capítulo, lo que se vuelve abyecto es el canon" (281). ¿Es justa esta declaración? ¿No sucede más bien que, en un proceder análogo al de Piglia, se domestica y neutraliza a Gombrowicz para integrarlo a un canon más aceptable a las sensibilidades modernas, hastiadas de venerables decencias nacionales? ¿Y cómo puede un canon ser honestamente abyecto ? Estos interrogantes se entroncan con la pregunta final de Mandolessi : “Qué lugar ocupa Gombrowicz en la tradición argentina ?" (282). La respuesta es esperable: debe otorgársele "un lugar abyecto" (283). Más allá de que esta respuesta resulta algo vaga e imprecisa, no es claro que sea, en rigor, una respuesta. El libro en su conjunto, sin embargo, sí da una respuesta muy válida a la pregunta, pero esta respuesta no está representada de modo conveniente en la "Conclusión".

Uno de los grandes aciertos metodológicos de Mandolessi es el de fundamentar toda afirmación relevante con un sólido y riquísimo sistema de citas. Una y otra vez, la voz de Gombrowicz viene a apuntalar la lectura de la autora. El diálogo entre Mandolessi y Gombrowicz (o entre Mandolessi y otros autores) es auténtico, y el lector puede participar de él. La técnica de close-reading, que puede llegar a cualquier profundidad sin perder nunca de vista el tenor concreto de los textos, muestra aquí todas sus posibilidades. La solvencia con la que Mandolessi maneja las fuentes primarias y secundarias es notable. Cabe esperar que este libro será de provecho para todo estudiante de Gombrowicz, sin duda, pero también para los especialistas en literatura argentina contemporánea. 


\section{NOTAS}

1. Este primer libro es Memorias del tiempo de la inmadurez (1933), colección de cuentos que se llamará Bakakaï a partir de su segunda edición (1957). Todas las citas de esta reseña pertenecen al libro de Mandolessi, del que sólo se indica el número de página.

2. Esto no significa, por supuesto, que esté ausente del todo. Se lo menciona especialmente en p. 218-219.

3. E.g., p. 123 : "Gombrowicz invoca un 'yo' despreciable, inferior, indecible"; o el estudio de la "automitologización paródica" (111).

\section{AUTORES}

\section{TOMÁS FERNÁNDEZ}

Universidad de Buenos Aires - CONICET 